\title{
A formação de professores para o ensino na área de Ciências da Natureza e a Base Nacional Comum Curricular
}

\author{
Teacher training for teaching in the field of Natural Sciences and the \\ Common National Curriculum Base
La formación de docentes para la docencia en el área de Ciencias Naturales y Base Curricular Nacional Común

Lisete Funari Dias, (lisetedias@ unipampa.edu.br)

Universidade Federal do Pampa (UNIPAMPA)

Maira Ferreira, (mmairaf@ gmail.com)

Universidade Federal de Pelotas (UFPel)

\begin{abstract}
Aline Souza da Luz, (alineluz@unipampa.edu.br)
Universidade Federal do Pampa (UNIPAMPA)

Julio Cesar Bresolin Marinho, (juliomarinho@unipampa.edu.br)

Universidade Federal do Pampa (UNIPAMPA)

Resumo: A pesquisa busca investigar como a formação inicial de professores da área de Ciências da Natureza para o Ensino Fundamental (EF) e Ensino Médio (EM) se apresenta no Projeto Pedagógico do Curso das licenciaturas em: Pedagogia; interdisciplinares em Educação do Campo e Ciências da Natureza; Física e Química, de uma IES do sul do Rio Grande do Sul, em relação ao previsto nas Diretrizes Curriculares Nacionais para a Formação de Professores, de 2015, 2019 e na Base Nacional Comum Curricular. Com base teórica em integração curricular e interdisciplinaridade, foram analisados documentos de políticas curriculares e PPC dos cursos, cujos dados passaram por Análise de Conteúdo, sendo a formação de professores discutida em três categorias relacionadas aos anos iniciais e finais do EF e EM. A categoria anos iniciais do EF aponta para interdisciplinaridade como possibilidade na formação do professor multidisciplinar de Pedagogia. Para os anos finais do EF e EM, é necessária uma formação de professores para a interdisciplinaridade, pois a matriz curricular dos cursos apresenta as disciplinas lado a lado, ficando a integração da área por conta dos formadores. Também diante da BNCC, a formação de professores aponta para a interdisciplinaridade, para o trabalho coletivo e para a integração curricular.
\end{abstract}

Palavras-chave: Licenciatura; Interdisciplinaridade; Integração Curricular; Diretrizes.

Abstract: The research investigated how the initial formation of teachers in the area of Natural Sciences for Elementary Education and High School is presented in the Pedagogical Project of the Course of the degrees in: Pedagogy; interdisciplinary in Rural Education and Nature Sciences; Physics and Chemistry, of an university in the south of Rio Grande do Sul, in relation to that provided for in the National Curriculum Guidelines for Teacher Training, of

Recebido em: 10/01/2021

Aceite em: 13/07/2021 
2015, 2019 and in the National Common Curricular Base. Theoretically based on curricular integration and interdisciplinarity, documents of curricular policies and Course Pedagogical Project of the courses were analyzed, whose data went through Content Analysis, with teacher training being discussed in three categories related to the initial and final years of Elementary Education and High School. The initial years of Elementary Education category points to interdisciplinarity as a possibility in the formation of the multidisciplinary teacher of Pedagogy. For the final years of Elementary Education and High School, teacher training is required for interdisciplinarity, as the curricular matrix of the courses presents the disciplines side by side, leaving the integration of the area on account of the trainers. Also in the face of BNCC, teacher training points to interdisciplinarity, collective work and curricular integration.

Keywords: Graduation; Interdisciplinarity; Curricular Integration; Guidelines.

Resumén: La investigación busca investigar como se presenta la formación inicial de docentes en el área de Ciencias Naturales para la Educación Primaria (EF) y Bachillerato (EM) en el Proyecto Pedagógico de la Licenciatura en: Pedagogía; cursos interdisciplinarios de Educación Rural y Ciencias Naturales; Física y Química, de una IES del sur de Rio Grande do Sul, en relación a lo previsto en las Directrices Curriculares Nacionales para la Formación Docente, 2015, 2019 y en la Base Curricular Nacional Común. Con base teórica en integración curricular e interdisciplinariedad, se analizaron documentos de política curricular y PPC de los cursos, cuyos datos pasaron por Análisis de Contenido, siendo discutida la formación docente en tres categorías relacionadas con los años inicial y final de Educación Física y Maestría. La categoría de Educación Física de Educación Infantil apunta a la interdisciplinariedad como posibilidad en la formación del docente multidisciplinar de Pedagogía. Para los últimos años de EF y EM, es necesario capacitar a los docentes para la interdisciplinariedad, ya que el plan de estudios de los cursos presenta las asignaturas en paralelo, siendo la integración del área responsabilidad de los capacitadores. También a la vista del BNCC, la formación docente apunta a la interdisciplinariedad, el trabajo colectivo y la integración curricular.

Palabras clave: Graduación; Interdisciplinariedad; Integración curricular; Directrices.

\section{INTRODUÇÃO}

Ao final do ano de 2019, os cursos de licenciatura, que tinham atualizado os Projetos Pedagógicos dos Cursos (PPC) com base nas Diretrizes Curriculares Nacionais para a Formação Inicial de Professores (DCNFP) (BRASIL, 2015), foram surpreendidos com a sua revogação e com a homologação de novas Diretrizes Curriculares Nacionais para a Formação Inicial de Professores (DCNFP) (BRASIL, 2019a). As novas DCNFP, aprovadas em 2019, trazem como mudança, em relação às anteriores, orientações e diretrizes para a formação de professores de acordo com o que é recomendado nos documentos da Base Nacional Comum

Recebido em: 10/01/2021

Aceite em: 13/07/2021 
Curricular para Educação Básica (BNCC) (BRASIL, 2017a; 2018a), contemplando um elenco de competências profissionais previstas na Base Nacional Comum para a Formação Inicial de Professores (BNCFP).

Diante do apontado por esses documentos oficiais, a formação inicial de professores para a Educação Básica, em especial para o ensino na área de Ciências da Natureza, foco desta pesquisa, tomou espaço nos cursos de licenciatura e nas escolas, em função da urgência em promover mudanças, ao mesmo tempo, em que as comunidades educativas procuraram compreender a recorrência de reformas educacionais, as quais não chegavam a se concretizar, quando uma outra reforma era anunciada, tal como ocorreu com as DCNFP nesses últimos anos.

Cabe esclarecer que não é nossa intenção aprofundar uma discussão em torno desses documentos oficiais, mas entendê-los como materialidade de políticas curriculares, demarcando uma relação entre a formação para Ciências da Natureza e os PPC de cinco cursos de licenciatura de uma Instituição Federal de Ensino Superior ${ }^{1}$ do sul do Rio Grande do Sul, a saber: licenciatura em Ciências da Natureza ${ }^{2}$, licenciatura em Educação do Campo (habilitação Ciências da Natureza); licenciatura em Química; licenciatura em Física; e licenciatura em Pedagogia (multidisciplinar), considerando que, nesse curso, os egressos também atuam em Ciências dos anos iniciais do Ensino Fundamental (EF).

O objetivo deste trabalho é investigar os PPC desses cursos e analisar como a formação inicial dos professores é apresentada, em relação ao atendimento do previsto pelas DCNFP/2015/2019 e pela BNCC, procurando entender discussões sobre currículo que estão além do conhecimento específico de cada curso, uma vez que as concepções teóricas e metodológicas implicadas no processo formativo são elementos que constituem a identidade dos futuros professores (SILVA, 2016).

Sobre os egressos dessas licenciaturas, pensamos que suas identidades vão se constituindo na área de formação como professor/a, sem que seja considerado no projeto de formação, por exemplo, a interdisciplinaridade como enfoque curricular. A construção curricular dos cursos em questão poderia trazer a relação dos conhecimentos entre as disciplinas, a qual faria parte na formação de professores, em "ações que valorizem o trabalho coletivo" (BRASIL, 2015, p. 7).

\footnotetext{
${ }^{1}$ Universidade Federal do Pampa (Unipampa)

${ }^{2}$ Campus Dom Pedrito

Recebido em: 10/01/2021

Aceite em: 13/07/2021
} 
Nesse sentido, trabalhar a integração entre componentes curriculares em dada área de atuação, seja em licenciaturas em campos de conhecimento, interdisciplinar ou multidisciplinar, poderia trazer maior familiaridade com a proposta preconizada pela BNCC no EF e Ensino Médio (EM) (LOPES, 2019).

A partir dessas considerações iniciais, justificamos a presente investigação na tentativa de responder se (e como) a interdisciplinaridade se apresenta nos PPC dos cursos de licenciatura estudados e de que modo contemplariam, ou não, princípios norteadores relacionados aos projetos interdisciplinares e à flexibilização curricular, entre outros (BRASIL, 2019a).

Para a interpretação dos resultados da pesquisa, considera-se a base teórica relacionada à interdisciplinaridade e à integração curricular em áreas do conhecimento, no âmbito da formação inicial dos professores que atuarão no ensino de Ciências da Natureza na educação básica.

\section{INTEGRAÇÃO CURRICULAR E INTERDISCIPLINARIDADE NA FORMAÇÃO INICIAL DE PROFESSORES}

As políticas curriculares para a educação básica, em especial a BNCC, também implicam em uma necessidade de reconfiguração curricular em cursos de licenciatura, pois indicam a necessidade de haver uma formação de professores que "dê conta" das reformas que chegam às escolas.

Diante do apontado pelas reformas curriculares analisadas nas DCNFP, buscamos apresentar pressupostos teóricos que nos auxiliassem a pensar as implicações na formação inicial de professores, com relação à importância da interdisciplinaridade. Segundo Fazenda (2013, p. 27), a interdisciplinaridade na formação de professores "requer competências relativas às formas de intervenção solicitadas e às condições para seu melhor exercício". No entanto, para o desenvolvimento dessas competências, há necessidade de saberes disciplinares, os quais possibilitariam a articulação entre conteúdos e práticas na atuação dos professores em disciplinas da área ou áreas.

As DCNFP (BRASIL, 2015, p. 7) referem-se que a organização curricular dos cursos deve ser fundamentada em "princípios de interdisciplinaridade, contextualização, democratização, pertinência e relevância social, ética e sensibilidade afetiva e estética”. Para

Recebido em: 10/01/2021

Aceite em: 13/07/2021 
as DCBFP/2019, a organização dos cursos de formação deve considerar "o compromisso com as metodologias inovadoras e os projetos interdisciplinares, flexibilização curricular, construção de itinerários formativos, projeto de vida dos estudantes, dentre outros (BRASIL, 2019a, p. 4).

Nessa perspectiva, buscamos entender questões que se relacionam a algumas propostas curriculares para a educação básica de acordo com Lopes (2019), que apresenta uma retrospectiva dos últimos vinte anos das propostas para o EM. A autora aponta que todas as reformas curriculares se assemelham e "têm expressado as lutas políticas por flexibilização curricular, usualmente associadas à inovação e maior adequação à contemporaneidade do social: interdisciplinaridade e contextualização, competências, temas transversais, currículo por ciclos" (LOPES, 2019, p. 62).

A organização curricular em áreas de conhecimento, a denominada integração curricular, assim como a indicação de uma base nacional comum curricular, já eram apontadas nas Diretrizes Curriculares Nacionais para o Ensino Médio de 1998: "a base nacional comum dos currículos do Ensino Médio seria organizada em três áreas de conhecimento": "Linguagens, Códigos e suas Tecnologias; Ciências da Natureza, Matemática e suas Tecnologias; Ciências Humanas e suas Tecnologias" (BRASIL, 1998, Art. 10).

Lenoir (1998, p. 50) define a integração curricular sob três pontos de vista: do educador, das aprendizagens e dos conhecimentos. Para o educador, significaria "um processo de articulação curricular dos programas de estudos e de gestão, sobre o plano didático e de planejamento da intervenção educativa"; para as aprendizagens, estaria relacionada aos "processos mediadores do trabalho de objetivação que se estabelece entre o sujeito e os objetos de aprendizagem"; e para os conhecimentos, estaria associada ao "resultado da aprendizagem em que se encontra o sujeito da aprendizagem”.

No caso da integração curricular em áreas do conhecimento, essas foram criadas na perspectiva de que campos específicos pudessem ser agrupados em torno de uma unidade mais abrangente do que uma única disciplina. Para o EM, os PCN (BRASIL, 2000) apresentaram a área de Ciências da Natureza como resultado da integração de quatro disciplinas: Biologia, Física, Química e Matemática, sendo que cada disciplina permanecia bem delimitada por temas estruturadores, como, por exemplo, na Física, a indicação do tema “Som, Imagem e Informação". Já na BNCC-EM (BRASIL, 2018), a área de Ciências da 
Natureza é composta pelas unidades temáticas: Matéria e Energia e Vida, e Terra e Cosmos, sem vinculação com alguma disciplina, como acontecia nos PCN. A BNCC apresenta, também três competências específicas e respectivas habilidades flexíveis a serem trabalhadas da $1^{\mathrm{a}}$ a $3^{\mathrm{a}}$ série, dando uma nova configuração à escola de nível médio, implicando, segundo Dias (2018), em uma nova organização do trabalho dos professores das disciplinas que compõem a área, que precisarão contar com espaço e tempo de planejamento de forma integrada na escola.

De acordo com Lopes (2008), a discussão sobre o currículo integrado no Brasil, apresentado na reforma do Ensino Médio de 1998, teve a finalidade de tornar o currículo menos fragmentado, mas, também, esteve alinhada a uma perspectiva de formar habilidades e competências consideradas essenciais aos processos produtivos, que Santomé (1998) apresenta, de maneira global, como sendo as influências dos modelos empresariais nos sistemas educacionais. Branco e Zanatta (2021), ao analisarem a atual reforma do Ensino Médio, também concluem que a reforma está alinhada aos interesses mercadológicos. O que não invalida o fato de que alguns eventos econômicos importantes, questões ambientais ou sociais só poderem ser explicados à luz de vários conhecimentos disciplinares, sendo importantes na formação de estudantes capazes de utilizar esses conhecimentos na resolução de problemas reais (SANTOMÉ, 1998).

Ainda, para Lopes (2008, p. 21), a organização do currículo em áreas do conhecimento não foi baseada na premissa de criar novas disciplinas ou excluí-las, mas "utilizar os conhecimentos de várias disciplinas para resolver um problema concreto ou compreender um determinado fenômeno sob diferentes pontos de vista". A autora complementa, dizendo que a organização do currículo em áreas do conhecimento poderia proporcionar "as condições necessárias para uma aprendizagem motivadora, na medida em que ofereça maior liberdade aos professores e alunos para a seleção de conteúdos mais diretamente relacionados aos assuntos ou problemas que dizem respeito à vida da comunidade" (p. 22).

Em relação ao EF, organizado em ciclos nos Parâmetros Curriculares Nacionais (PCNEF) (BRASIL, 1997), as áreas do conhecimento correspondem às disciplinas de Língua Portuguesa, Matemática, Ciências Naturais, História, Geografia, Arte e Educação Física. Os conteúdos de Ciências Naturais foram organizados em eixos temáticos (Terra e Universo; Vida e Ambiente; Ser Humano e Saúde; Tecnologia e Sociedade), semelhante à organização apresentada pela BNCC-EF (BRASIL, 2017a), quando se organiza em torno de unidades

Recebido em: 10/01/2021

Aceite em:13/07/2021 
temáticas (Matéria e Energia; Vida e Evolução; e Terra e Universo). Outra semelhança se dá entre os Temas Transversais dos PCN e os Temas Contemporâneos Transversais da BNCC. Importante destacar que as Ciências Naturais, sendo considerada como área ou como disciplina, normalmente é trabalhada apenas por um/a professor/a de Ciências, geralmente com formação em Ciências Biológicas ou formação interdisciplinar, tais como as licenciaturas em Ciências da Natureza com habilitação em áreas do conhecimento. Para Lopes (2019, p. 62), na proposta de currículo integrado para o EF, embora as disciplinas escolares possam ser vistas como desvinculadas aos interesses dos alunos, a BNCC-EF reafirma sua importância ao reforçar o "fortalecimento das relações entre elas".

De acordo com o documento da BNCC (BRASIL, 2018a), o currículo integrado, organizado por áreas do conhecimento, também auxiliaria no planejamento e avaliação curricular, de modo a evitar a fragmentação nas práticas de sala de aula e na vida dos estudantes.

Diante do exposto até aqui, entende-se que as reformas curriculares na educação básica, envolvendo a interdisciplinaridade e a integração curricular, têm efeitos nos processos de formação de professores e, nesse sentido, Ferreira (2001) defende uma condição importante para que a interdisciplinaridade aconteça: "o trabalho coletivo dos professores", sendo considerado um desafio, tanto para os professores em exercício, pelas condições de trabalho, quanto para os docentes formadores em cursos de licenciatura, por ser a formação inicial baseada em disciplinas isoladas, não voltada para o trabalho interdisciplinar e integrado (MOZENA e OSTEMANN, 2014). Além disso, para Santomé (1998), existe a dificuldade em promover um trabalho coletivo, seja pela resistência dos professores em articular suas especialidades com os demais, seja justificado pelo atendimento às avaliações externas e processos de ingresso ao Ensino Superior, que ainda tem um direcionamento para o conhecimento disciplinar.

\section{PROCEDIMENTOS METODOLÓGICOS DA PESQUISA}

A pesquisa se caracteriza como qualitativa e os procedimentos técnicos são documentais, recorrendo "a materiais que ainda não receberam tratamento analítico" (GIL, 2008, p. 51). Nessa pesquisa, as fontes são documentos oficiais curriculares e Projetos Pedagógicos da Universidade Federal do Pampa. Os documentos passaram por uma análise

Recebido em: 10/01/2021

Aceite em: 13/07/2021 
documental, sendo a primeira etapa, a análise do contexto em que foram produzidos: datas, autoria na criação e na expressão de ideias.

O primeiro critério para escolha dos PPC tem relação com as licenciaturas que habilitam para o ensino de Ciências, nos anos iniciais e finais do EF e aquelas que habilitam para as disciplinas de Física, Química e Biologia no EM. O critério de exclusão se refere aos PPC que ainda não foram atualizados de acordo com as DCNFP/2015. Sendo assim, analisamos o PPC da Licenciatura em Pedagogia; Licenciatura em Educação do CampoCiências da Natureza; Licenciatura em Ciências da Natureza ${ }^{3}$; Licenciatura em Química; e Licenciatura em Física, excluindo as licenciaturas em Ciências da Natureza ${ }^{4}$ e Ciências Biológicas.

Inicialmente, os documentos oficiais analisados e confrontados com PPC foram os seguintes: Base Nacional Comum Curricular; Resolução $n^{\circ} 2$, de $1^{\circ}$ de julho de 2015; e Resolução CNE/CP n ${ }^{\circ}$ 2, de 20 de dezembro de 2019. No decorrer da análise, foi necessário consultar outros documentos oficiais, tais como: Parâmetros Curriculares Nacionais Ensino Fundamental e Ensino Médio; Resolução n 1, de 15 de maio de 2006; Resolução nº 4, de 13 de julho de 2010; Resolução CNE/CP nº 2, de 22 de dezembro de 2017; Lei nº 13.415 de 16 de fevereiro de 2017 (BRASIL, 2017b); Parecer CNE/CEB nº 3/2018; Portaria nº 1.432, de 28 de dezembro de 2018; Temas contemporâneos e transversais na BNCC.

Por fim, os dados passaram por Análise de Conteúdo (AC), conforme descrita por Bardin (1977), assim como, por um conjunto de técnicas de análise propostas por Moraes (1999):

i) Preparação do material: foram identificados documentos oficiais com pré-análise dos textos e sistematização das ideias iniciais. A partir daí, evidenciamos o objetivo da pesquisa que é investigar os PPC dos cursos e analisar como a formação inicial desses professores, com relação a interdisciplinaridade, é apresentada em atendimento ao previsto nas DCNFP/2015/2019 e BNCC. Após essa etapa, foi necessária a leitura em outros documentos oficiais relativos à educação básica e formação inicial nos cursos de Pedagogia.

ii) Transformação do conteúdo em unidades: foi realizada a releitura de todos os materiais, identificando neles as unidades de análise, isolando cada uma no contexto da formação de professores para o ensino na área de Ciências da Natureza nas etapas da educação básica (EF

\footnotetext{
${ }^{3}$ Campus Dom Pedrito

${ }^{4}$ Campus Uruguaiana

Recebido em: 10/01/2021

Aceite em: $13 / 07 / 2021$
} 
e EM). A exploração dos documentos oficiais confrontou os PPC em uma seleção de componentes da matriz curricular com respectivas ementas e carga horária, assim como metodologias ou componentes curriculares integradores.

iii) Categorização: Na seleção e organização, os dados foram classificados em três categorias definidas a priori: Ensino de Ciências nos anos iniciais; Ensino de Ciências nos anos finais do EF; e Ensino na área de Ciências da Natureza do EM.

iv) Descrição em forma de textos relativos a cada uma das categorias.

v) Interpretação das unidades de significados restrita ao que é dito nos documentos oficiais no confronto com os PPC e com a fundamentação teórica apresentada a priori.

\section{RESULTADOS E DISCUSSÕES}

Realizadas as etapas da análise, os resultados são descritos e discutidos a partir das categorias definidas a priori: Ensino de Ciências: formação de professores para interdisciplinaridade nos anos iniciais do EF; Ensino de Ciências: formação de professores para a interdisciplinaridade nos anos finais do EF; Formação de professores na área de Ciências da Natureza e o Novo Ensino Médio.

4.1 Ensino de Ciências: formação de professores para interdisciplinaridade nos anos iniciais do EF

De acordo com as DCNFP/2015, o ensino de Ciências nos anos iniciais do EF fica por conta dos cursos de Pedagogia, que deve considerar no PPC, "os tempos dedicados à constituição de conhecimento sobre os objetos de ensino" em uma carga horária de $2200 \mathrm{~h}$ dentro de um total de $3200 \mathrm{~h}^{5}$ (BRASIL, 2015, Art. 13). Já, para as atuais DCNFP/2019, os objetos de ensino compõem os grupos I e II em uma carga horária de $2400 \mathrm{~h}$ dentro do total de $3200 \mathrm{~h}^{6}$. O grupo I (800h) abrange os conhecimentos científicos, educacionais e pedagógicos que fundamentam a educação e o grupo II (1600h) contempla a aprendizagem dos conteúdos, unidades temáticas e objetos de conhecimento com ênfase em competências previstas na BNCC.

\footnotetext{
${ }^{5}$ I- 400 horas de prática como componente curricular; II - 400 horas dedicadas ao estágio supervisionado; III pelo menos 2200 horas dedicadas às atividades formativas estruturadas pelos núcleos; IV - 200 horas de atividades teórico-práticas.

${ }^{6}$ I- 800 horas, conhecimentos científicos, educacionais e pedagógicos. II - 1600 horas, para a aprendizagem dos conteúdos específicos das áreas, componentes, unidades temáticas e objetos de conhecimento da BNCC; III 800 horas: a) 400 horas para o estágio supervisionado; e b) 400 horas para a prática dos componentes curriculares.
}

Recebido em: 10/01/2021

Aceite em:13/07/2021 
No caso dos cursos de Pedagogia, há também as DCN específicas, nas quais são indicadas que o egresso deverá estar apto a ensinar os componentes "Língua Portuguesa, Matemática, Ciências, História, Geografia, Artes e Educação Física, de forma interdisciplinar e adequada às diferentes fases do desenvolvimento humano" (BRASIL, 2006, Art. $5^{\circ}$ ). Essa determinação está alinhada às orientações dos PCN-EF (BRASIL, 1997), de aproximação das disciplinas por meio dos Temas Transversais. De acordo com as Diretrizes Curriculares Nacionais da Educação Básica (DCNEB) (BRASIL, 2010), a organização do currículo deve se dar em áreas de conhecimento, reafirmada na BNCC-EF, quando aponta as áreas: Linguagens (Língua Portuguesa, Artes, Educação Física e Língua Inglesa); Matemática ${ }^{7}$; Ciências da Natureza (Química, Física, Biologia, Astronomia); Ciências Humanas (História e Geografia); e Ensino Religioso.

Ao confrontarmos as DCN/2006 para cursos de Pedagogia com as DCNFP/2015, percebemos um alinhamento ao "projeto formativo nas instituições de educação sob uma sólida base teórica e interdisciplinar que reflita a especificidade da formação docente, assegurando organicidade ao trabalho das diferentes unidades que concorrem para essa formação" (BRASIL, 2015, p. 4).

Com relação ao PPC analisado, o curso de Pedagogia prevê os princípios da interdisciplinaridade, da contextualização e da flexibilização curricular na formação acadêmica, concepção trazida do Projeto de Desenvolvimento Institucional (PDI) da Unipampa, contando com corpo docente e recursos de infraestrutura, a exemplo de laboratórios de imagem e som, informática, brinquedoteca e biblioteca, entre outros. Com esses recursos, o PPC prevê a formação de um egresso com o perfil crítico, consciente e capaz de transformar realidades (UNIPAMPA, 2016a).

Com relação à BNCC, à DCNFP/2019 e às áreas do conhecimento das quais terá habilitação, entendemos que há a recomendação de que a formação desse professor deve estar articulada às competências gerais da BNCC e também com as competências e habilidades específicas de cada área. Apesar de entendermos um direcionamento para uma formação que contemple a interdisciplinaridade e a integração na área de conhecimento ou entre as áreas, as novas diretrizes denominam a formação desses professores de multidisciplinar, com a justificativa de que um único professor deve ensinar todos os componentes, o que seria um equívoco.

${ }^{7}$ A Matemática é uma área do conhecimento representada por uma única disciplina.

Recebido em: 10/01/2021

Aceite em: 13/07/2021 
O termo multidisciplinar utilizado vai de encontro ao que as DCN dos cursos de Pedagogia orientam, pois na multidisciplinaridade a "comunicação entre as diversas disciplinas é reduzida a um mínimo" ou a uma "mera justaposição de disciplinas, que de maneira simultânea abordariam elementos comuns" (SANTOMÉ, 1998, p. 71). Ser um professor multidisciplinar, nesse caso, significaria atuar em todas as disciplinas, porém de forma fragmentada, não estabelecendo, necessariamente, relações entre elas.

Uma formação de professores para dar conta das DCNFP/2019 com relação a BNCC, que se apresenta organizada em áreas do conhecimento, para atender a formação básica comum e a parte diversificada, deve prever pressupostos da interdisciplinaridade. A parte diversificada, representada obrigatoriamente pelos Temas Contemporâneos e Transversais (TCT) (BRASIL, 2019b), apresentados em seis macro áreas (Cidadania e Civismo, Ciência e Tecnologia, Economia, Meio Ambiente, Multiculturalismo e Saúde), é direcionada para a interdisciplinaridade, mas, como já dito, necessita que sejam trabalhados à luz de vários conhecimentos disciplinares.

A articulação entre os TCT e os conteúdos da BNCC, envolvendo problemas sociais e ambientais, abrange o contexto da comunidade em que está inserida a escola, em uma dimensão do local ao mundial, o que indica a necessidade da formação de professores contemplando práticas interdisciplinares em projetos integradores, mas devendo partir de uma atitude interdisciplinar, na qual o professor se dedica a pesquisar para conhecer mais, possibilitando técnicas de ensino inovadoras para os estudantes (FAZENDA, 2013).

Em uma análise dos conteúdos de Ciências com relação ao PPC/2016 do curso de Pedagogia, encontramos um único componente curricular da área de Ciências da Natureza, intitulado "Ensinar e Aprender Ciências Naturais" (60h) apresentando, na ementa, considerações sobre "as concepções de ciência, ambiente e sociedade [...]; Conteúdos de Ciências Naturais para o Ensino Fundamental em uma perspectiva da alfabetização científica [...] investigação, a experimentação, a ludicidade, a Educação Ambiental" (UNIPAMPA, 2016a, p. 105). Nessa ementa, fica claro o objetivo de formação de professores para além da aprendizagem dos conteúdos de Ciências, entendendo a necessidade das estratégias pedagógicas, porém alicerçadas em seus respectivos referenciais teóricos. Como observado, esse único componente curricular não apresenta conteúdos de Ciências, os quais, na BNCCEF, são representados por meio dos campos da Física, Química, Biologia e Astronomia.

Recebido em: 10/01/2021

Aceite em: 13/07/2021 
Segundo Lunardi e Emmel (2021), os licenciandos em Ciências Biológicas, em uma reflexão sobre ensinar Ciências, deixam claro três motivos para ensinar Ciências: Ciências para o cotidiano; Ciências para preservar o meio ambiente; e Ciências para ser crítico, motivos que estão de acordo com conteúdo do documento da BNCC, sendo apresentados desde os anos iniciais do Ensino Fundamental na perspectiva de que, na "vivência diária das crianças e sua relação com o entorno, elas interagem com a luz, som, calor, eletricidade e umidade, entre outros elementos" (BRASIL, 2018a, p. 327). Tais elementos, que constam nas unidades temáticas da BNCC, são acompanhados da indicação do desenvolvimento das habilidades previstas para uma compreensão contextualizada com o cuidado da integridade física da criança e da vida do Planeta, o que justificaria a aquisição desses conhecimentos específicos da área de Ciências na formação de professores.

Diante da análise da BNCC-EF em relação ao PPC do curso de Pedagogia, consideramos que os conteúdos de Ciências da BNCC são bem densos e complexos, para serem trabalhados em apenas $60 \mathrm{~h}$. Com relação à prática interdisciplinar, essa seria possível no Núcleo de Estudos Integradores da organização curricular do curso, contemplando experiências de aprendizagem em anos iniciais, o que ampliaria a carga horária para ensinar conteúdo da área de Ciências Naturais, integrado as demais áreas.

Interpretando os dados que buscamos apresentar sobre a formação de professores para o ensino de Ciências nos anos iniciais do EF, em um curso de Pedagogia, apontamos possibilidades para o exercício da docência, em uma dimensão interdisciplinar e contextualizada. Tais possibilidades são aquelas que objetivam atender os pressupostos para a caracterização do perfil do egresso, conforme se apresenta no PPC, estando de acordo com os princípios de formação elencados nas DCNFP (BRASIL, 2019a).

\subsection{Ensino de Ciências: formação de professores para a interdisciplinaridade nos} anos finais do EF

Os professores que atuam no ensino de Ciências dos anos finais do EF serão egressos dos cursos de licenciatura em Ciências Biológicas ou de licenciaturas interdisciplinares em Ciências Naturais ou Ciências da Natureza. Para este trabalho, analisamos o PPC de duas licenciaturas que habilitam para os anos finais do EF e mesmo sendo denominadas de interdisciplinares, não compreendemos que tenha esse enfoque, uma vez que a matriz curricular se alinha com resultados de uma pesquisa em PPC de diversas licenciaturas

Recebido em: 10/01/2021

Aceite em: 13/07/2021 
interdisciplinares no Brasil (LUZ, 2018). Em sua pesquisa, a autora evidencia que as disciplinas da área estão dispostas lado a lado na matriz curricular do curso, com caráter multidisciplinar, sem necessariamente, implicar em formação para ações interdisciplinares. A partir desses resultados e sabendo que os PPC das licenciaturas que analisamos estão adequados às DCNFP/2015, buscamos analisar se (e como) a formação interdisciplinar é explicitada nos componentes curriculares e no perfil do egresso.

O curso de licenciatura em Ciências da Natureza da UNIPAMPA - Campus Dom Pedrito habilita para a área de Ciências da Natureza nos anos finais do EF e EM e apresenta, no PPC, o perfil do egresso de forma que atenda alguns pressupostos, entre eles, "desenvolver habilidades necessárias para o ensino na área de Ciências da Natureza a partir da contextualização e da problematização dentro de uma perspectiva interdisciplinar" (UNIPAMPA, 2019a, p. 40). No entanto, mesmo que a matriz curricular do curso esteja constituída em eixos integradores a cada semestre, não encontramos evidências de que os componentes da área de Ciências da Natureza pudessem estar integrados, mostrando a incapacidade de haver ruptura com a disciplinaridade e o conteudismo. Uma das possibilidades de integração poderia ocorrer, por iniciativa individual do professor, em componentes de Práticas Pedagógicas.

O segundo PPC analisado foi o de licenciatura em Educação do Campo, com habilitação para a área de Ciências da Natureza nos anos finais do EF e EM. Nesse curso, também observamos a matriz curricular organizada em componentes integrados a um eixo integrador a cada semestre. A carga horária do curso é organizada em Regime de Alternância, isto é, dois terços reservados ao Tempo Universidade e o restante ao Tempo Comunidade, momento que o curso propõe projetos integrados ao tema do eixo, área de Ciências da Natureza e Educação do Campo. Quanto ao perfil do egresso, esse deve atender alguns pressupostos, entre eles: "desenvolver projetos pedagógicos interdisciplinares na área de Ciências da Natureza em espaços educativos [...]” (UNIPAMPA, 2019b, p. 37).

Analisando o perfil dos egressos dessas duas licenciaturas, da forma como está descrito, entendemos que há previsão da realização de práticas interdisciplinares, o que poderia ser uma forma de minimizar a presença de práticas fortemente disciplinares durante a graduação, vistos como obstáculos aos futuros professores quanto à possibilidade de realização de inovações educacionais, que exigem colaboração entre equipes e articulação dos conhecimentos (SANTOMÉ, 1998; MOZENA e OSTEMANN, 2014).

Recebido em: 10/01/2021

Aceite em: 13/07/2021 
Ao atender os pressupostos da interdisciplinaridade, os cursos contemplariam as DCNFP/2015 em uma "compreensão ampla e contextualizada de educação e educação escolar, visando assegurar a produção e difusão de conhecimentos de determinada área [...] na perspectiva de garantir, com qualidade, os direitos e objetivos de aprendizagem" (BRASIL, 2015, p. 3). Com relação às DCNFP/2019, entendemos que não há alinhamento com a formação de um professor de Ciências para os anos finais do EF articulada às competências gerais da BNCC e também com as específicas de cada área com respectivas habilidades em uma proposta totalmente integrada durante os quatro anos finais.

Anterior à BNCC-EF, o ensino de Ciências dos anos finais do EF, na maior parte das escolas, previa conteúdos de Biologia do $6^{\circ}$ ao $8^{\circ}$ ano, enquanto os de Química e Física eram previstos no $9^{\circ}$ ano. Com a BNCC-EF, os conteúdos de Ciências passaram a ser organizados em unidades temáticas (Matéria e Energia; Vida e Evolução; Terra e Universo), distribuídos do $6^{\circ}$ ao $9^{\circ}$ ano, com orientação semelhante aos PCN-EF que, no final dos anos de 1990, indicavam que os conteúdos não deveriam ser desenvolvidos isoladamente. Além disso, esses conteúdos estão organizados "na perspectiva da continuidade das aprendizagens e da integração com seus objetos de conhecimento ao longo dos anos de escolarização" (BRASIL, 2018a, p. 300).

$\mathrm{Na}$ análise dos conteúdos da BNCC-EF, com relação à matriz curricular dos cursos que habilitam para a área de Ciências da Natureza, esses oferecem formação em Física, Química e Biologia, para a "ampliação da relação dos jovens com o ambiente" (BRASIL, 2018a, p. 328). No entanto, acreditamos que a formação de professores de Ciências, planejada pelos cursos analisados, não tem a pretensão de formar um biólogo, um químico ou um físico para sala de aula, mas sim a formação para a integração na área, de forma que facilite a transposição do conhecimento específico de cada um dos campos e que se torne significativo aos estudantes.

Para uma análise além de conteúdo, o documento da BNCC orienta o aumento de complexidade do conhecimento desde os anos iniciais do EF até o EM. Tal recomendação pode ser vista com relação à Astronomia, cujos objetos de conhecimento vão sendo aprofundados até o $9^{\circ}$ ano do EF. Isso mostra que a percepção do desenvolvimento dos saberes, de menor a maior complexidade, pode ser esperada na formação de professores, o que consideramos um ganho na formação dos professores.

Recebido em: 10/01/2021

Aceite em: 13/07/2021 
A análise do ensino de Ciências dos anos finais, a partir da BNCC-EF, também aponta para a importância da interdisciplinaridade, considerando que os conteúdos, provavelmente serão trabalhados por um único professor. Logo, é importante que a matriz curricular dos cursos de licenciatura se ocupe, dentre muitos conhecimentos e saberes, de uma formação que vá além da multidisciplinaridade, possibilitando aos professores que, além de atentarem para as disciplinas relacionadas com as Ciências, sejam capazes de ter atitude interdisciplinar, com planejamento em equipe e que essa atitude seja respaldada pela organização escolar e por boas condições de trabalho.

\subsection{Formação de professores na área de Ciências da Natureza e o Novo Ensino} Médio

O ensino na área de Ciências da Natureza no EM é desempenhado por professores formados nas licenciaturas em Física, Química, Ciências Biológicas ou em interdisciplinares na área de Ciências da Natureza, sendo atribuído a esses, ministrar aulas de Física, Química e Biologia, organizadas isoladamente na matriz curricular do EM, com aproximações em eventuais projetos interdisciplinares.

Os PPC das licenciaturas analisadas nesta pesquisa são os mesmos da categoria anos finais do EF que também habilitam para a docência no EM, somadas às licenciaturas em Química e Física. Além das licenciaturas interdisciplinares que mencionam a interdisciplinaridade como competência no perfil do egresso, somente o curso de licenciatura em Química refere a interdisciplinaridade e a integração curricular nas competências gerais, a exemplo de: “Transitar pelas fronteiras entre a sua área de conhecimento e outras áreas, bem como a das tecnologias atuais, sendo capaz de demarcar seus campos específicos e, sobretudo, de pôr em prática a interdisciplinaridade" (UNIPAMPA, 2016b, p. 31).

Analisando os PPC das licenciaturas em Física (UNIPAMPA, 2018) e Química (UNIPAMPA, 2016b), campus Bagé, temos que ambos também foram elaborados em consonância com os princípios gerais do PDI da Unipampa e da concepção de formação acadêmica da universidade, tendo a interdisciplinaridade como princípio específico. No entanto, para que esse princípio fosse colocado em prática, buscamos ver essa possibilidade na matriz curricular, mas encontramos o termo interdisciplinaridade apenas nas referências bibliográficas de um único componente curricular denominado Organização do Trabalho Pedagógico na Escola, com $60 \mathrm{~h}$ teóricas e 30h de prática como componente curricular.

Recebido em: 10/01/2021

Aceite em: 13/07/2021 
Relacionadas ao componente, as práticas de integração curricular entre as áreas de conhecimento poderiam ser possíveis, pois a oferta semestral se organiza para turmas mistas e envolvem todas as licenciaturas do campus, nas áreas de Matemática, Ciências da Natureza (Química e Física) e Linguagens (Letras Português, Música e Língua Estrangeira).

Conforme já mencionado, com relação à formação de professores em cursos interdisciplinares, não é possível evidenciar na ementa dos componentes curriculares uma possível integração na área de Ciências da Natureza e demais áreas do conhecimento, nem mesmo nos componentes que contemplam carga horária de Práticas Pedagógicas.

Com relação a organização da carga horária das licenciaturas, estabelecida nas DCNFP/2019, vimos que pouco se altera em relação às DCNFP/2015, mas como já dito na categoria EF, para a formação de professores que atuarão no EM, as DCNFP/2019 preveem componentes interdisciplinares ou áreas de estudos, conteúdo da área em componentes que estejam de acordo com as unidades temáticas, objetos de conhecimento e respectivas competências e habilidades previstas na BNCC.

Para justificar a discussão sobre a importância da integração curricular e da interdisciplinaridade nas licenciaturas pesquisadas, trouxemos uma descrição sobre a proposta de reforma do novo Ensino Médio (EM). O documento diz que a reforma contempla uma formação geral básica que se organiza em torno dos conteúdos da BNCC de acordo com as áreas do conhecimento (1800h, no máximo) e a parte flexível representada nos Itinerários Formativos (1200h, no mínimo). A proposta ainda prevê a ampliação da carga horária do EM com a implementação gradual do modelo de Ensino Médio em tempo integral (BRASIL, 2018c).

Com relação à BNCC-EM, a área de Ciências da Natureza e suas tecnologias está organizada em duas unidades temáticas: Matéria e Energia; e Vida, Terra e Cosmos. Quanto ao conteúdo específico, a área se apresenta em três competências com respectivas habilidades a serem desenvolvidas nas três séries do EM. A primeira competência se relaciona à unidade temática Matéria e Energia, com sete habilidades; a segunda, à unidade temática Vida, da Terra e do Cosmos, contemplando nove habilidades; e a terceira contempla aplicações do conhecimento científico e tecnológico, desenvolvendo dez habilidades. Vinculados às três competências específicas da área de Ciências da Natureza, os objetos do conhecimento aparecem no texto de forma a serem organizados de maneira flexível nas três séries, conforme

Recebido em: 10/01/2021

Aceite em: 13/07/2021 
indica o código 13, incluído no código das habilidades. Como exemplo dessa organização, referimos os objetos de conhecimento da habilidade 01 relacionada à competência 1 , da área de Ciências da Natureza e suas Tecnologias (EM13CNT101): Transformações e conservação da energia, Conservação da quantidade de movimento; Fluxo de energia e de matéria nos ecossistemas; Metabolismo energético, Ligações e reações químicas, Leis ponderais e estequiometria.

Nesse sentido, como já dito, Lopes (2019) critica a forma como está sendo trazida a integração curricular na BNCC-EM, pois essa teria o objetivo de "quebrar" a centralidade das disciplinas no processo de ensino-aprendizagem. Além disso, podemos dizer que essa forma de organização curricular dificulta o planejamento das escolas, com impacto negativo na distribuição do trabalho docente na escola e na formação dos estudantes do EM.

Tal organização da BNCC-EM indica uma proposta de formação em cursos de licenciatura em torno dos conteúdos básicos da BNCC. Diante disso, haveria necessidade de o perfil do egresso contar com a capacidade de trabalhar colaborativamente de maneira interdisciplinar, contemplando a integração curricular na área e/ou entre áreas (SANTOMÉ, 1998; MOZENA e OSTEMANN, 2014). No contexto da prática de formação inicial de professores, a formação de equipes de trabalho é entendida como um valor agregado à formação humana e profissional.

Independente de ser, ou não, organizado em áreas, um exemplo do movimento que se contrapõe à fragmentação do conhecimento seria o trabalho em equipe de professores e licenciandos envolvendo aprendizagens por projetos com objetivos comuns entre as áreas do conhecimento, contemplando Temas Contemporâneos e Transversais da BNCC, especialmente em componentes práticos, conforme já mencionamos no decorrer do texto e nas categorias anteriores.

Quando defendemos o trabalho em equipe, não queremos desconsiderar a concepção de disciplina escolar, mas, sim, mostrar as implicações de mudanças na organização curricular do EM sem que pensemos uma formação de professores capaz de realizar trabalho em equipe para o planejamento de projetos interdisciplinares, pois "alterar a organização curricular, implica modificar identificações docentes" (LOPES, 2019, p. 63).

Práticas interdisciplinares nas licenciaturas seriam condição necessária considerando a proposta do novo Ensino Médio, cujos Itinerários Formativos e sua organização "por meio da

Recebido em: 10/01/2021

Aceite em:13/07/2021 
oferta de diferentes arranjos curriculares", a saber: Linguagens e suas Tecnologias; Matemática e suas Tecnologias; Ciências da Natureza e suas Tecnologias; Ciências Humanas e Sociais Aplicadas; Formação Técnica e Profissional; e a partir de diversas atividades educativas (projetos, oficinas, eletivas etc) (BRASIL, 2018b). Com a prática do trabalho em equipe, por exemplo em projetos, estaríamos nos aproximando de ações metodológicas interdisciplinares, associadas à inter-relação entre os campos de conhecimento, bem-vinda em pesquisas ou solução de problemas reais que podem ser trabalhados em projetos (SANTOMÉ, 1998).

Diante desse estudo, percebemos um grande desafio às escolas em organizarem seus currículos, ditos flexíveis, o que também será um desafio para a formação inicial de professores, cabendo, também, às licenciaturas proporcionarem, durante a formação inicial, uma visão crítica sobre vários aspectos da organização do EM na escola.

\section{CONSIDERAÇÕES FINAIS}

Tomamos como objetivo deste trabalho, a investigação dos PPC de cinco cursos de licenciatura da Unipampa, uma Instituição Federal de Ensino Superior do sul do Rio Grande do Sul, a saber: licenciatura em Ciências da Natureza, licenciatura em Educação do Campo (habilitação Ciências da Natureza); licenciatura em Química; licenciatura em Física; e licenciatura em Pedagogia, procurando analisar como a formação inicial dos professores é apresentada, em relação ao atendimento do previsto pelas DCNFP/2015/2019 e pela BNCC.

A análise de documentos oficiais relativos às políticas curriculares para a educação básica nos permitiu discutir as implicações para a reconfiguração dos cursos de formação inicial de professores, pois a nova proposta de organização escolar requer que a formação de professores "dê conta" desse modelo de escola em termos de integração curricular e interdisciplinaridade.

Sendo assim, procuramos, na análise dos PPC, relacionar a organização dos cursos, não somente com o conhecimento específico da BNCC, mas também com possíveis previsões de práticas interdisciplinares implicadas no processo, de forma a evitar uma formação fortemente disciplinar durante a graduação, o que concordamos que se constitua como um obstáculo aos futuros professores quando a prática exigir trabalho colaborativo em equipe interdisciplinar.

Recebido em: 10/01/2021

Aceite em: $13 / 07 / 2021$ 
Observamos que os PPC, atualizados pelas DCNFP/2015, apresentam os princípios da interdisciplinaridade, ficando a prática por conta dos formadores. Nessa perspectiva, para as licenciaturas que habilitam para a área de Ciências da Natureza nos anos finais do EF e EM, reconhecemos a importância da prática de trabalho em equipe durante a formação inicial, o que poderia ser efetivado em projetos interdisciplinares na área. Para o EM, o desafio é maior, pois os conteúdos básicos da BNCC e os Itinerários Formativos, previstos para o novo Ensino Médio, sendo ofertados em termos de projetos, oficinas e componentes curriculares, requerem olhar para a formação em cursos de licenciatura. Para os anos iniciais do EF, o PPC do curso de Pedagogia, cuja formação é multidisciplinar, além de formação para o Ensino de Ciências, deve possibilitar que faça relação entre as disciplinas, no contexto da escola e no mundo contemporâneo.

Diante do exposto, entendemos ser necessário que os cursos de formação de professores conheçam e considerem os saberes previstos pela BNCC, no entanto, não podemos pensar uma formação focada no que é apresentado na Base, visto que é comum as políticas curriculares possuírem um "prazo de validade", sendo, periodicamente, substituídas. Os professores ficam nas escolas, enquanto os currículos nacionais são alterados e, dessa forma, os saberes trabalhados nas licenciaturas devem transcender a BNCC, para que os futuros professores de Ciências possam ter uma formação que os capacite a exercer a docência com autonomia.

Pretendemos, assim, discutir possibilidades de refletir sobre os PPC das licenciaturas envolvidas de forma crítica ao que se apresenta nas DCNFP/2019, principalmente com relação à $\mathrm{BNCC}$ e ao direcionamento que a formação de professores poderá ter em função dessas políticas.

\section{REFERENCIAS}

BARDIN, L. Análise de conteúdo. Lisboa: Edições 70, 1977.

BRANCO, E.; ZANATTA, S. BNCC e Reforma do Ensino Médio: implicações no ensino de Ciências e na formação do professor. Revista Insignare Scientia-RIS, v. 4, n. 3, p. 58-77, 3 mar. 2021.

BRASIL. Parâmetros curriculares nacionais: introdução aos Parâmetros Curriculares Nacionais Ensino Fundamental. Brasília, DF: MEC/SEF, 1997. Disponível em: http://portal.mec.gov.br/seb/arquivos/pdf/livro01.pdf. Acesso em 20 mai. 2020.

Recebido em: 10/01/2021

Aceite em: 13/07/2021 
Resolução CEB no 3, de 26 de junho de 1998. Instituiu as Diretrizes Curriculares Nacionais para o Ensino Médio. Diário Oficial da União: seção 1, Brasília/DF, p.21, 05 ago. 1998.

Parâmetros Curriculares Nacionais: Ensino Médio - Parte I - Bases Legais. Brasília, DF: MEC/SEMT, 2000. Disponível em: http://portal.mec.gov.br/seb/arquivos/pdf/blegais.pdf. Acesso em 20 mai. de 2020

Resolução CNE/CP n ${ }^{\circ}$, de 15 de maio de 2006. Institui as Diretrizes Curriculares Nacionais para o curso de graduação em Pedagogia. Diário Oficial da União: seção 1, Brasília/DF, p.11, 16 mai. 2006.

Resolução CNE/CP n ${ }^{\circ}$, de 13 de julho de 2010. Institui as Diretrizes Curriculares Nacionais gerais para a educação básica. Diário Oficial da União: seção 1, Brasília/DF, p.824, 14 jun. 2010.

Resolução CNE/CP n ${ }^{\circ}$ 2, de $1^{\circ}$ de julho de 2015. Define as Diretrizes Curriculares Nacionais para a formação inicial em nível superior. Diário Oficial da União: seção 1, Brasília/DF, p. 8-12, 2 jul. 2015.

Resolução CNE/CP n ${ }^{\circ}$, de 22 de dezembro de 2017. Institui a implantação da Base Nacional Comum Curricular. Diário Oficial da União: seção 1, Brasília/DF, p. 41 a 44, 22 dez. 2017a.

Lei n. 13.415, de 16 de fevereiro de 2017. Altera as Leis n. 9.394, de 20 de dezembro de 1996, 11.494, de 20 de junho 2007, CLT aprovada pelo Decreto-Lei n. 5.452, de $1^{\circ}$ de maio de 1943 e o Decreto-Lei n. 236, de 28 de fevereiro de 1967; revoga a Lei n. 11.161, de 5 de agosto de 2005; e institui a Política de Fomento à Implementação de Escolas de Ensino Médio em Tempo Integral. Diário Oficial da União: seção 1, Brasília/DF, p.1, 17 fev. 2017b.

Base nacional comum curricular. Brasília, DF: MEC/SEB/CNE, 2018a.

Disponível em:

http://basenacionalcomum.mec.gov.br/images/BNCC_EI_EF_110518_versaofinal_site.pdf. Acesso 20 mai.2020.

Parecer CNE/CEB no 3/2018, 8 de novembro de 2018. Define a atualização das Diretrizes Curriculares Nacionais para o Ensino Médio. Diário Oficial da União: seção 1, Brasília/DF, p. 49, 21 nov. 2018b.

Resolução CNE/CP nº 2, de 20 de dezembro de 2019a. Define as Diretrizes Curriculares Nacionais para a Formação Inicial de Professores para a Educação Básica e institui a Base Nacional Comum para a Formação Inicial de Professores da Educação Básica. Diário Oficial da União: seção 1, Brasília/DF, p. 46-49, 15 abr. 2020.

DIAS, L. F. Formação continuada para professores da área de ciências da natureza no Pacto Nacional pelo Fortalecimento do Ensino Médio/Unipampa: "o que se mostra" da valorização pela formação? Tese (Doutorado) - Programa de Pós- Graduação em Educação em Ciências. Universidade Federal do Rio Grande do Sul, Porto Alegre, 2018.

Recebido em: 10/01/2021

Aceite em: 13/07/2021 
FAZENDA, I. C. O que é interdisciplinaridade. São Paulo: Cortez, 2013.

FERREIRA, S. L. Introduzindo a noção de interdisciplinaridade. In: FAZENDA, I. (org.). Práticas Interdisciplinares na Escola. 7. ed. São Paulo: Cortez, 2001.

GIL, A. C. Métodos e Técnicas de Pesquisa Social. 6. ed. São Paulo. Atlas, 2008.

LENOIR, Y. Didática e Interdisciplinaridade: uma complementaridade necessária e incontornável. In: FAZENDA, I. (org.) Didática e interdisciplinaridade. São Paulo: Papirus, 1998.

LOPES, A. C. Políticas de integração curricular. Rio de Janeiro: EDUERJ, 2008.

LOPES, A. C. Itinerários formativos na BNCC do Ensino Médio: identificações docentes e projetos de vida juvenis. Retratos da Escola, 13(25), 59-75, 2019.

LUNARDI, L.; EMMEL, R. Investigando os motivos para ensinar Ciências às novas gerações. Revista Insignare Scientia, v. 4, n. 3, p. 179-193, 3 mar. 2021.

LUZ, A. S. da. As licenciaturas interdisciplinares no cenário nacional: implantação e processo. 2018. 405 f. Tese (Doutorado em Educação) - Programa de Pós-Graduação em Educação. Faculdade de Educação. Universidade Federal de Pelotas, Pelotas, 2018.

MORAES, R. Análise de conteúdo. Revista Educação, Porto Alegre, v. 22, n. 37, p. 7-32, 1999.

MOZENA, E.; OSTEMANN, F. Uma revisão bibliográfica sobre a interdisciplinaridade no ensino das ciências da natureza. Ensaio Pesquisa em Educação em Ciências, Belo Horizonte, v. 16, n. 2, p. 185 - 206, ago. 2014.

SANTOMÉ, J. T. Globalização e interdisciplinaridade: O currículo integrado. Porto Alegre: Artmed, 1998.

SILVA, T. T. Documentos de Identidade: Uma introdução às teorias do currículo. Belo Horizonte: Autêntica, 2016.

UNIVERSIDADE FEDERAL DO PAMPA. Projeto Pedagógico do Curso de Pedagogia. Jaguarão: Unipampa, 2016a.

UNIVERSIDADE FEDERAL DO PAMPA. Projeto Pedagógico do Curso de Química. Bagé: Unipampa, 2016b.

UNIVERSIDADE FEDERAL DO PAMPA. Projeto Pedagógico do Curso de Física. Bagé: Unipampa, 2018.

UNIVERSIDADE FEDERAL DO PAMPA. Projeto Pedagógico da Licenciatura em Educação do Campo. Dom Pedrito: Unipampa, 2019a.

Recebido em: 10/01/2021

Aceite em: 13/07/2021 
UNIVERSIDADE FEDERAL DO PAMPA. Projeto Pedagógico da Licenciatura em Ciências da Natureza. Dom Pedrito: Unipampa, 2019b

Recebido em: 10/01/2021

Aceite em: 13/07/2021 